\title{
Determination of Manganese in Sludge, Alloy, and Soil by Tungsten Coil Atomic Emission Spectrometry
}

\section{Mario Henrique Gonzalez \& Luana Novaes Santos}

To cite this article: Mario Henrique Gonzalez \& Luana Novaes Santos (2015) Determination of Manganese in Sludge, Alloy, and Soil by Tungsten Coil Atomic Emission Spectrometry, Analytical Letters, 48:15, 2434-2445, DOI: 10.1080/00032719.2015.1033723

To link to this article: https://doi.org/10.1080/00032719.2015.1033723

Accepted author version posted online: 15

Jun 2015.

Published online: 27 Jul 2015.

Submit your article to this journal $\pi$

Џ Article views: 63

View Crossmark data $\complement$

Citing articles: 2 View citing articles $\lceil\nearrow$ 


\title{
Atomic Spectroscopy \\ DETERMINATION OF MANGANESE IN SLUDGE, ALLOY, AND SOIL BY TUNGSTEN COIL ATOMIC EMISSION SPECTROMETRY
}

\author{
Mario Henrique Gonzalez ${ }^{1}$ and Luana Novaes Santos ${ }^{2}$ \\ ${ }^{1}$ Department of Chemistry and Environmental Sciences, Institute of \\ Biosciences, Letters, and Exact Sciences, State University of São Paulo \\ (UNESP), São José do Rio Preto, São Paulo, Brazil \\ ${ }^{2}$ State University of Santa Cruz, Ilhéus, Bahia, Brazil
}

A tungsten coil atomic emission spectrometer (WCAES) was developed and evaluated for the determination of manganese in industrial sludge, alloy, and soil. The system employed a coil extracted from a 150 watts 15 volts commercial slide projector light bulb and a simple power supply that provided a constant current to the coil. The analytical signals were resolved and detected using a Czerny-Turner spectrometer and a charge coupled device. Three manganese emission lines were detected simultaneously. Using different emission lines, limits of detection for manganese varied from 0.54 to 0.65 milligram per liter, and relative standard deviations for manganese at 5 milligrams per liter varied from 5.9 to 8.5 percent $(\mathrm{n}=10)$. Summation of the Mn signals improved the detection limit to 0.17 milligram per liter and decreased the relative standard deviation to 1.7 percent. Spectral interferences were observed in the presence of $\mathrm{Al}, \mathrm{Ca}, \mathrm{K}$, and $\mathrm{Na}$. The accuracy was determined using two certified reference materials, and the results obtained by WCAES were in agreement with those obtained by inductively coupled plasma-optical emission spectrometry at the 95 percent confidence level.

Keywords: Certified reference materials; Inductively coupled plasma optical emission spectrometry (ICP OES); Tungsten coil atomic emission spectrometry (WCAES)

\section{INTRODUCTION}

Emission and absorption measurements are performed for several purposes. The wavelength of the spectral lines emitted or absorbed by chemical species in their excited or fundamental states provides information about the structure of the atoms or molecules. In addition, the relative intensities of the radiation can be used for

Received 15 October 2014; accepted 21 March 2015.

Address correspondence to Mario Henrique Gonzalez, Departamento de Química e Ciências Ambientais, Instituto de Biociências, Letras e Ciências Exatas, Universidade Estadual Paulista "Júlio de Mesquita Filho”, Rua Cristóvão Colombo, 2265, Jardim Nazareth, 15054-000, São José do Rio Preto, SP, Brazil. E-mail: gonzalez@ibilce.unesp.br

Color versions of one or more of the figures in the article can be found online at www.tandfonline. com/lanl. 
quantitative analysis. Plasmas, flames, and graphite furnaces are commonly used to atomize and excite analytes. Alternatively, metal devices have been used as electrothermal atomizers (Hou and Jones 2002). The main limitations of metallic atomizers as sources for absorption/emission measurements include the lack of suitable commercial instruments, their nonisothermal behavior, and the occurrence of interferences (Nóbrega et al. 1995; Oliveira et al. 2000; Queiroz et al. 2002). However, the ability of these atomizers to provide portable in situ analysis and simultaneous multi-element determination makes them ideal for field applications. Tubes, coils, boats, and wires have been successfully used as metallic atomizers in atomic absorption spectrometry (AAS). For atomic emission measurements, several studies conducted in Japan investigated the use of molybdenum tubes (Suzuki and Ohta 1981, 1982; Ohta 1987) and tungsten tubes (Suzuki and Ohta 1985; Ohta, Itoh, and Mizuno 1991).

The use of tungsten coils for analytical atomization dates back to the early 1970s. Typically, a tungsten device is employed in one of two modes: as an electrothermal atomizer or as a vaporizer. Tungsten has attractive physical properties, such as good electrical conductivity, ductility, high melting point (3407 degree Celsius), and low vapor pressure (Emsley 1989; Weast 1989; Hou and Jones 2002). It is resistant to chemical attack and can only be significantly degraded by a mixture of hydrofluoric and nitric acids or an alkaline fusion oxidant (Cotton and Wilkinson 1982). Some of the favorable characteristics of a tungsten atomizer include: lack of memory effects due to metal surface homogeneity; long coil lifetime; low power requirements, enabling use of a simple power supply or battery; low emission in the visible and ultraviolet regions of the electromagnetic spectrum (Ribeiro, Arruda, and Cadore 2002); low cost; the possibility of achieving temperatures up to 3200 degree Celsius; and no need for a cooling system or an automatic sampler (Berndt and Schaldach 1988; Giné et al. 1993). Tungsten has been used as an atomizer for ETAAS, ETAFS, and ETV in order to develop hyphenated techniques (Hou et al. 2001).

Unexpected signals recorded during atomic absorption were reported (Rust et al. 2006), and these authors were the first to describe tungsten coil atomic emission spectrometry (WCAES). Atomic emission lines were observable for elements with relatively low ionization potentials, despite non-isothermal behavior and low temperatures of the gas phase. A commercial 15 volts/150 watts coil was arranged in a borosilicate glass furnace with quartz windows, under a constant flow of a mixture of 90 percent $\mathrm{Ar}$ and 10 percent $\mathrm{H}_{2}$. Heating was achieved with a power source, and the emission of radiation from the filament was resolved using a high-resolution Czerny-Turner monochromator with a charge coupled device (CCD). The optical arrangement was greatly simplified by the elimination of the need for an external radiation source.

A portable, rugged, and compact design WCAES was described, and the coil was extracted from an inexpensive 24 volts $/ 250$ watts commercial light bulb. The atomization cell, single lens, and a hand-held CCD spectrometer were arranged on a ceramic base. Fifteen elements were analyzed: $\mathrm{Al}, \mathrm{Ba}, \mathrm{Cr}, \mathrm{Cs}, \mathrm{Cu}, \mathrm{Eu}, \mathrm{Fe}, \mathrm{Ga}$, $\mathrm{Li}, \mathrm{Mg}, \mathrm{Mn}, \mathrm{Rb}, \mathrm{Sr}, \mathrm{V}$, and $\mathrm{Yb}$. The precision (determined as the relative standard deviation) ranged from 4.3 to 8.4 percent. Detection limits ranged from 0.04 to 1500 micrograms per liter, and recoveries of elements in certified reference materials were between 72 and 147 percent ( $\mathrm{Gu}$ et al. 2011).

Simultaneous determination of cobalt in polluted water using multiple emission lines from 340.5 to 352.7 nanometers was carried out using a simple tungsten coil 
atomic emission device (Donati et al. 2010). This strategy improved the precision $(2.2$ percent relative standard deviation) and accuracy (102 percent) for the analysis of a polluted water reference material.

A portable tungsten coil atomic emission spectrometer for the simultaneous determination of metals in water and soil shows the instrument provided excellent performance in the visible to near-infrared, and its multielement capability made it attractive for field applications. Fifteen elements were used to characterize this portable WCAES instrument (Gu, Hanna, and Jones 2011).

A new atomization cell for trace metal determinations by tungsten coil atomic absorption spectrometry (WCAAS) and tungsten coil atomic emission spectrometry (WCAES) was developed by Donati, Wildman, and Jones (2011). The configuration provided better control of the radiation reaching the detector together with a more isothermal environment in the atomizer. The method presented was simple, inexpensive, compact, sensitive, potentially portable, and offered an interesting alternative to traditional spectroanalytical methods.

An in situ digestion method for matrix decomposition under strong oxidizing conditions (hydrogen peroxide and nitric acid) was optimized to determine $\mathrm{Ca}$ in juice, water, and coconut oil samples. Evaluation was made of interferences caused by the presence of $\mathrm{Na}, \mathrm{K}$, and $\mathrm{Mg}$ in these matrices (Santos et al. 2012).

In the present work, WCAES was used to determine Mn in industrial sludge, alloy, and soil samples. The accuracy of the method was determined by comparing the results with those obtained using ICP OES, as well as by the analysis of certified reference materials.

\section{EXPERIMENTAL}

\section{WCAES Configuration}

The atomizer used was a tungsten coil filament extracted from a commercially available 150 watts/15 volts slide projector light bulb (Osram, Dortmund, Germany) connected to two copper electrodes. The filament was housed inside a glass atomization cell with fused quartz windows (Figure 1). A constant potential solid-state power supply (Anacom Científica, São Bernardo do Campo, São Paulo, Brazil) was employed to resistively heat the coil during the process. A purge gas composed of 10 percent $\mathrm{H}_{2}$ mixed with 90 percent Ar was used. This gas mixture prevented coil

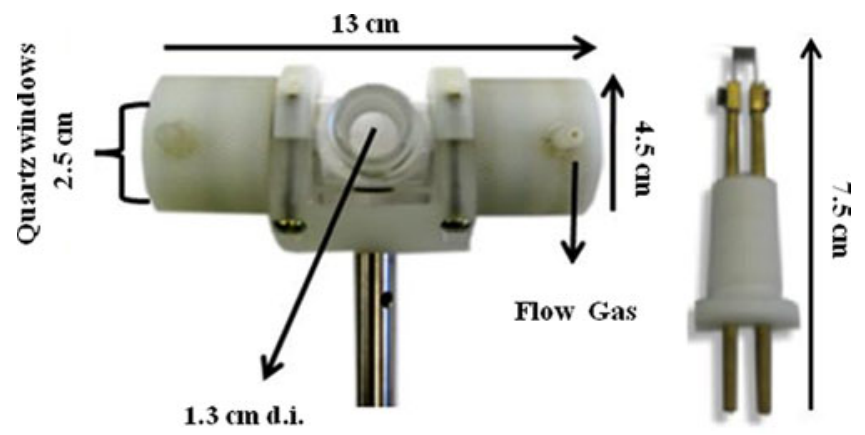

Figure 1. Schematic of the atom cell. 


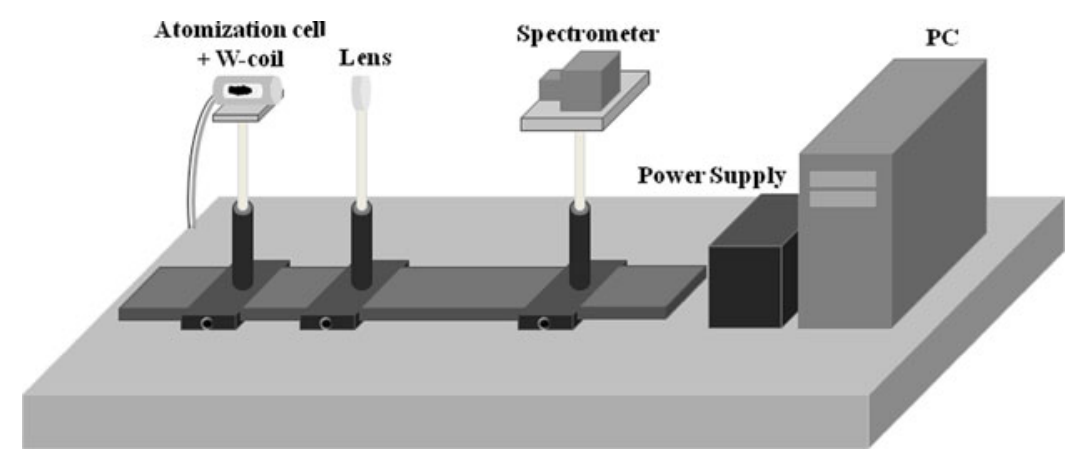

Figure 2. Diagram of the tungsten coil atomic emission spectrometer.

oxidation and promoted oxide reduction to improve atomization, and the purge gas cooled the coil at the end of the atomization cycle. The radiation emitted above the atomizer was collected with a fused silica lens and guided into the entrance slit of a handheld spectrometer (HR 4000, Ocean Optics, Dunedin, FL, USA). The CCD detector consisted of a two-dimensional array of 3648 pixels, and the system provided a spectral window of approximately 50 nanometers, with a fixed entrance slit width of 50 micrometers and typical resolution of approximately 0.02 nanometer. A schematic diagram of the WCAES system is presented in Figure 2.

\section{Optimization of Instrumental Parameters}

The monitored emission lines were at 403.07, 403.31, and 403.44 nanometers, and their intensities were 27000, 19000, and 11000 a.u., respectively (Donati, Wildman, and Jones 2011). The atomic emission lines monitored in WCAES are dependent on the viewing position of the coil atomizer. This position is carefully determined in order to maximize the analyte emission and minimize the background emission. In this work, the influence of the coil position relative to the spectrometer entrance slit was investigated in order to improve the sensitivity for Mn. Two different coil orientations were evaluated, based on the signal intensities obtained for a 10milligram per liter Mn solution. A sample aliquot (20 microliters) was placed directly on the atomizer using a micropipette (10-100 microliters, Eppendorf, Brinkman, Westbury, NY, USA). The purge gas flow rate was maintained at 1.0 liter per minute. Manganese atomization-excitation was achieved by applying 12 volts to the tungsten coil.

\section{Heating Program}

The heating program used (Table 1) is critical in the development of atomization-based methods, and in the present work was established by monitoring the voltage applied during the drying and atomization steps. The atomization program consisted of seven steps. In the first five steps, the applied voltage was successively decreased in order to dry the sample while minimizing the potential for sample losses caused by overheating. Atomization and data collection occurred during the sixth step. 
Table 1. Heating program for manganese

\begin{tabular}{lccc}
\hline Step & Applied voltage (volt) & Time (second) & Read \\
\hline 1 & 0.70 & 10 & No \\
2 & 0.65 & 10 & No \\
3 & 0.60 & 10 & No \\
4 & 0.50 & 5 & No \\
5 & 0.40 & 5 & No \\
6 & 13.0 & 3 & Yes \\
\hline
\end{tabular}

\section{Reagents, Reference Solutions, and Samples}

Distilled-deionized water (18 megaohms centimeter resistivity) was obtained from a Milli-Q system (Millipore, Bedford, MA, USA) and was used to prepare all the solutions. All glassware was immersed in 10 percent (v/v) $\mathrm{HNO}_{3}$ for thirty-six hours and rinsed with distilled-deionized water before use. Reagent grade concentrated nitric acid (Carlo Erba, Italy), 30 percent $(v / v)$ hydrogen peroxide (Mallinckrodt, Mexico), hydrochloric acid, hydrofluoric acid, and boric acid (Synth, São Paulo, Brazil) were employed for acid digestion and extraction of the samples. Reference solutions containing $\mathrm{Al}, \mathrm{Ca}, \mathrm{Co}, \mathrm{Fe}, \mathrm{K}, \mathrm{Na}, \mathrm{Mn}$, and $\mathrm{Ni}$ were prepared by diluting single element Titrisol stock solutions (Merck, Darmstadt, Germany). Certified reference materials of industrial sludge (SRM 2782) and San Joaquim Soil (SRM 2709), both produced by the National Institute of Standards and Technology (Gaithersburg, MD, USA), were used for development of the procedure and evaluation of accuracy.

\section{Microwave Digestion and Extraction}

A microwave system equipped with perfluoroalkoxy vessels (MLS, Milestone, Sorisole, Italy) was employed for sample digestion. Soil (220 milligrams) and alloys (100 milligrams) were digested using microwave-assisted heating with 5 milliliters of aqua regia and 4 milliliters of $\mathrm{HF}$ in closed vessels. After digestion, 24 milliliters of a 4 percent (watt per volt) boric acid was added.

The use of hydrofluoric acid in conjunction with other acid mixtures is an established method for the digestion of solid and sludge samples containing silica. However, the presence of hydrofluoric acid can cause deterioration of the components of the sample introduction system, and the torch of the analyzer and the tungsten coil. This problem can be mitigated by using boric acid to mask the free fluoride ions in the solution, as well as to facilitate dissolution of precipitated fluorides.

After digestion, the digests were diluted to 50 milliliters with water. The microwave oven heating program consisted of the following steps: Two minutes at 300 watts; two minutes at 0 watt; five minutes at 500 watts; five minutes at 800 watts; two minutes at 0 watt; two minutes at 500 watts; and five minutes at 800 watts. The maximum temperature was 215 degree Celsius.

The industrial sludge samples (250 milligrams) were also submitted to microwave-assisted digestion. However, it was not possible to analyze these samples by WCAES, due to excessive dilution. Extraction was therefore performed using a 
low-intensity ultrasonic water bath (USC-1400, Unique, Indaiatuba, SP, Brazil). Samples (500 milligrams) were mixed with 9.0 milliliters of $\mathrm{HNO}_{3}+\mathrm{HCl}+\mathrm{HF}+\mathrm{H}_{3} \mathrm{BO}_{3}$ (the same reagents employed in the microwave digestion) and extraction was continued for six hours. The extracted solutions were diluted to 10 milliliters with water.

\section{ICP OES}

For comparison purposes, all samples were analyzed by inductively coupled plasma optical emission spectrometry (ICP OES) with axial viewing (Vista PROCCD, Varian, Mulgrave, Australia). The instrumental parameters included the following: 40 megahertz generator frequency; 1.2 kilowatts applied radio frequency power; 15 liters per minute plasma gas flow; 1.5 liters per minute auxiliary gas flow; 0.9 liter per minute nebulizer gas flow; cyclonic spray chamber; concentric nebulizer; and 0.8 milliliter per minute sample flow rate. The following emission wavelengths (nanometer) were monitored: Mn II 257.610; Mn II 259.372; and Mn I 279.482.

\section{RESULTS AND DISCUSSION}

The positioning of the coil is critical for the monitoring of atomic emission lines. The optimal viewing position is where the background signal is minimal and the gas phase temperature provides enhanced metal atomization ( $\mathrm{Gu}$ et al. 2011). The sensitivity of the Mn determination was investigated using different positions of the tungsten coil. When the coil was positioned in a vertical orientation (Figure $3 \mathrm{a})$, the background signal increased and caused saturation of the detector, and no analytical signal was observed. In a horizontal orientation (Figure 3b), analytical
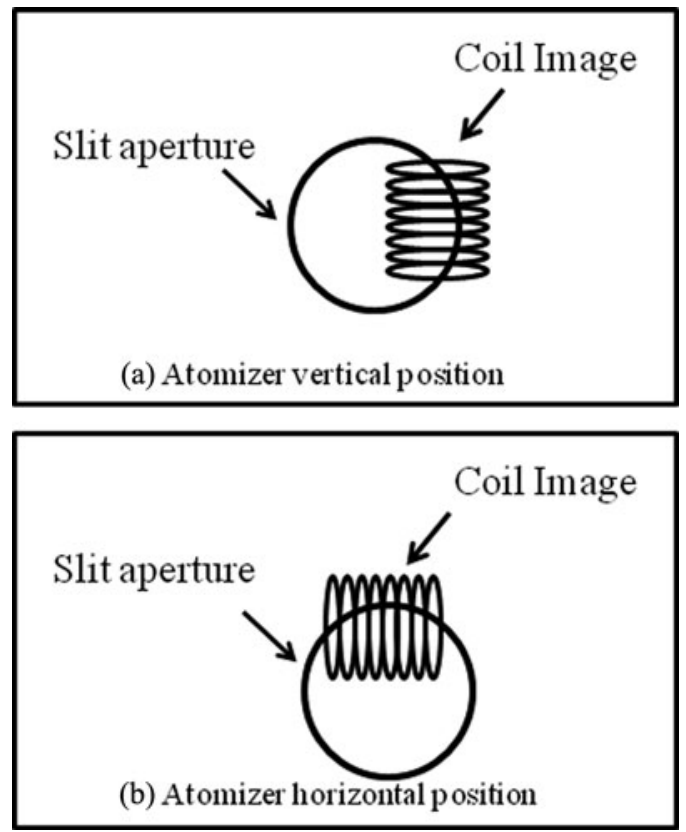

Figure 3. Atomizer position relative to the spectrometer entrance slit: (a) vertical and (b) horizontal. 
signals were observed for regions slightly above the atomizer and opposite to the purge gas inlet, and the best sensitivity for $\mathrm{Mn}$ was achieved in this position. Maximum manganese emission occurred at the second frame, and the signal returned to the baseline immediately after the third frame, when only the background signal was observed and the detector became saturated. The best sensitivity was achieved using an integration time of 200 milliseconds. Blank spectra were subtracted from spectra collected during the atomization process.

The effect of purge gas flow rate on Mn atomization-excitation was evaluated. It was observed that the magnitude of the Mn emission changed when the flow rate was varied from 0.7 to 1.3 liters per minute. In this work, a gas flow rate of 1.0 liter per minute was adopted. A lack of hydrogen at low flow rates may affect the reducing atmosphere around the coil, while at high flow rates the atomization cloud may be diluted and rapidly dissipate.

Signal intensity is directly proportional to the applied voltage, and strong blackbody emission can saturate the detector, so that it is impossible to detect the analytical signal. At the same time, blackbody emission from the coil improves the signal-to-noise ratio. The voltage applied during the atomization step was optimized using a 10 milligrams per liter Mn reference solution, with monitoring of the emission signals at 403.0, 403.3, and 403.4 nanometers (Figure 4). As expected, a higher voltage provided more energy for atomization and excitation. However, when a voltage of 14 volts was applied, there was an increase in blackbody emission from the coil, and it was difficult to resolve the Mn emission. Intense and resolved emission signals were obtained at 13 volts. All the spectral data represent the intensities obtained for the Mn emission signals after subtracting the analytical blank.

As previously reported (Queiroz et al. 2002), it is known that the nonisothermal environment of an open atomizer causes difficulties with matrix interferences. A

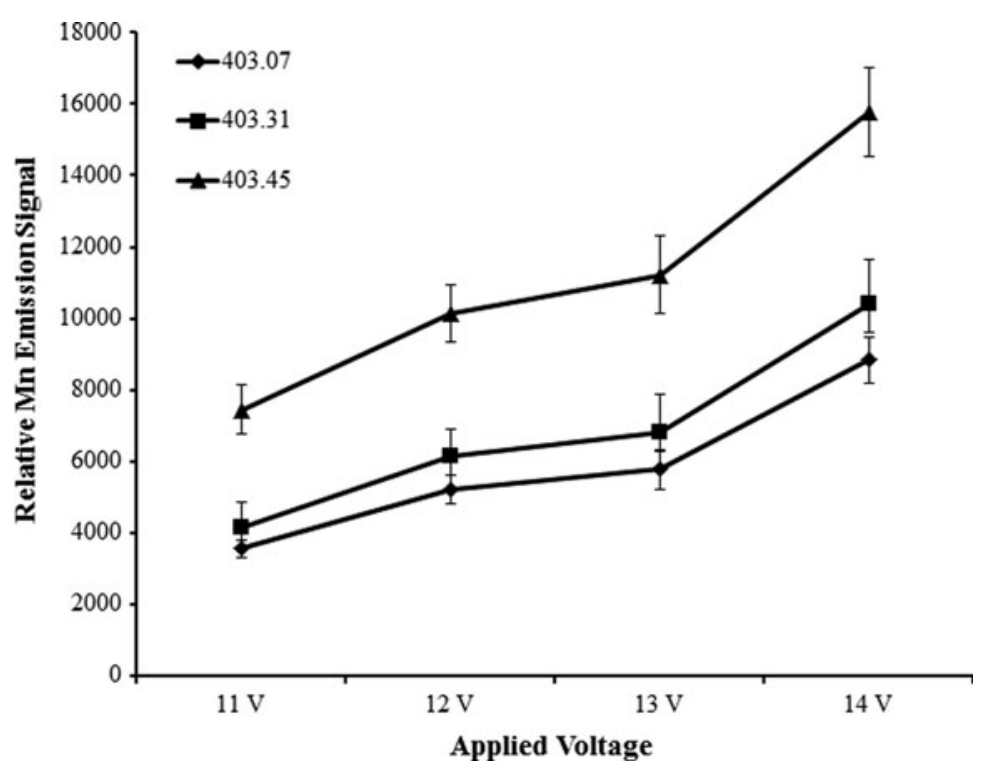

Figure 4. Manganese emission as a function of applied voltage. 
matrix interference study was therefore carried out to in order evaluate the effects of $\mathrm{Al}, \mathrm{Ca}, \mathrm{Co}, \mathrm{K}, \mathrm{Na}$, and Ni. Six-single element interference solutions were prepared each containing 5 or 50 milligrams per liter $\mathrm{Mn}$, and one another element: Al, Ca, $\mathrm{Co}, \mathrm{K}, \mathrm{Na}$ and $\mathrm{Ni}$ in the same concentration. In addition, one multielement interference solution containing 5 and 50 milligrams per liter of all elements was determined (Table 2). Manganese emission at 403.07, 403.31, and 403.44 nanometers for the mixed solutions were compared with those for the interferent-free 5 and 50 milligrams per liter Mn solutions. When 5 milligrams per liter Mn was used, the presence of $\mathrm{Ca}$ and $\mathrm{Na}$ produced positive interferences, with gains in the manganese intensity of 22-47 percent, compared to the interference-free $\mathrm{Mn}$ signal. At the higher concentration level (50 milligrams per liter), only Ni caused decreases greater than 10 percent in $\mathrm{Mn}$ emission, compared to the interference-free Mn signal. The presence of $\mathrm{K}$ shows gains in the Mn signals of approximately 5-22 percent. The most serious interference was when all six elements were present, which resulted in signal increases of between 19 and 46 percent. This interference was probably due to a combination of spectral overlap and matrix effects in the solution or gas phase (Donati et al. 2010). In terms of interference effects, no differences were observed between the three wavelengths studied.

After establishing the optimal conditions, the analytical figures of merit for manganese were determined using aqueous standards. The limit of detection (LOD) and the limit of quantification (LOQ) were calculated according to the recommendations of the International Union of Pure and Applied Chemistry (IUPAC), which stipulates $3 \times \mathrm{S}_{\text {blank }} / \mathrm{slope}$ and $10 \times \mathrm{S}_{\text {blank }} / \mathrm{slope}$, respectively. The repeatability and precision were reported as the relative standard deviation (RSD) for ten consecutive measurements of a 5-milligram per liter manganese solution. Analytical calibration curves were constructed in the range from 1.0 to 100

Table 2. Per cent interferences caused by $\mathrm{Al}, \mathrm{Ca}, \mathrm{Co}, \mathrm{K}, \mathrm{Na}$, and $\mathrm{Ni}$ for the determination of 5 and 50 milligrams per liter $\mathrm{Mn}$ at 403.07, 403.31, and 403.45 nanometers

\begin{tabular}{lccc}
\hline & & Mn & \\
\cline { 2 - 4 } & 403.07 & 403.31 & 403.45 \\
Interferences & nanometers & nanometers & nanometers \\
\hline 5 milligrams per liter $\mathrm{Al}$ & +3 & +7 & +11 \\
50 milligrams per liter $\mathrm{Al}$ & +5 & +8 & +4 \\
5 milligrams per liter Ca & +22 & +27 & +32 \\
50 milligrams per liter Ca & +2 & +4 & +1 \\
5 milligrams per liter Co & -2 & +4 & +2 \\
50 milligrams per liter Co & -7 & -7 & -7 \\
5 milligrams per liter $\mathrm{K}$ & +12 & +16 & +21 \\
50 milligrams per liter $\mathrm{K}$ & +5 & +5 & +7 \\
5 milligrams per liter $\mathrm{Na}$ & +38 & +40 & -2 \\
50 milligrams per liter $\mathrm{Na}$ & -2 & -2 & -3 \\
5 milligrams per liter $\mathrm{Ni}$ & -11 & -8 & -15 \\
50 milligrams per liter $\mathrm{Ni}$ & -14 & -13 & +38 \\
5 milligrams per liter $\mathrm{Al}+\mathrm{Ca}+\mathrm{Co}+\mathrm{K}+\mathrm{Na}+\mathrm{Ni}$ & +40 & +46 & +19 \\
50 milligrams per liter & +24 & +31 & \\
$\quad$ Al + Ca + Co $+\mathrm{K}+\mathrm{Na}+\mathrm{Ni}$ & & & \\
\hline
\end{tabular}


Table 3. WCAES analytical figures of merit

\begin{tabular}{lcccc}
\hline Analytical figures of merit & $\begin{array}{c}403.07 \\
\text { nanometers }\end{array}$ & $\begin{array}{c}403.31 \\
\text { nanometers }\end{array}$ & $\begin{array}{c}403.45 \\
\text { nanometers }\end{array}$ & $\begin{array}{c}\text { Summed } \\
\text { signals }\end{array}$ \\
\hline Linear correlation coefficient & 0.9993 & 0.9998 & 0.9935 & 0.9987 \\
$\begin{array}{l}\text { Limit of detection (milligram per liter) } \\
\text { Limit of quantification (milligram per } \\
\quad \text { liter) }\end{array}$ & 0.54 & 0.64 & 0.65 & 0.17 \\
Relative standard deviation (percent) & 5.9 & 2.12 & 2.16 & 0.58 \\
\hline
\end{tabular}

Table 4. Manganese determined by tungsten coil atomic emission spectrometry (WCAES) and inductively coupled plasma optical emission spectrometry (ICP OES) $(n=3)$

\begin{tabular}{lcccccc}
\hline Samples & Certified & $\begin{array}{c}\text { ICP OES 257.61 } \\
\text { nanometers }\end{array}$ & $\begin{array}{c}403.07 \\
\text { nanometers }\end{array}$ & $\begin{array}{c}403.31 \\
\text { nanometers nanometers }\end{array}$ & $\begin{array}{c}403.45 \\
\text { signals }\end{array}$ \\
\hline $\begin{array}{c}\text { Industrial sludge } \\
\text { (NIST 2782) }\end{array}$ & $\begin{array}{c}538 \pm 17 \text { milligrams } \\
\text { per kilogram }\end{array}$ & $532 \pm 47$ & $556 \pm 45$ & $599 \pm 81$ & $613 \pm 54$ & $549 \pm 29$ \\
$\begin{array}{c}\text { San Joaquim Soil } \\
\text { (NIST 2709) }\end{array}$ & $\begin{array}{c}300 \text { milligrams per } \\
\text { kilogram }\end{array}$ & $301 \pm 27$ & $287 \pm 25$ & $276 \pm 26$ & $298 \pm 22$ & $291 \pm 17$ \\
Alloy & max. 2.5 percent & $2.7 \pm 0.083$ & $2.05 \pm 0.018$ & $2.67 \pm 0.021$ & $2.93 \pm 0.028$ & $2.69 \pm 0.018$ \\
\hline
\end{tabular}

milligrams per liter, and the linear correlation coefficients of the curves were between 0.9935 and 0.9998 . Incomplete separation was observed between 403.3 and 403.4 nanometers, due to the low resolution of the spectrometer. According to the manufacturer (Ocean Optics), the theoretical resolution of the spectrometer is 0.02 nanometer, but nonetheless it was not possible to separate the signals at 403.3 and 403.4 nanometers. The sum of the intensities of the signals was therefore used to

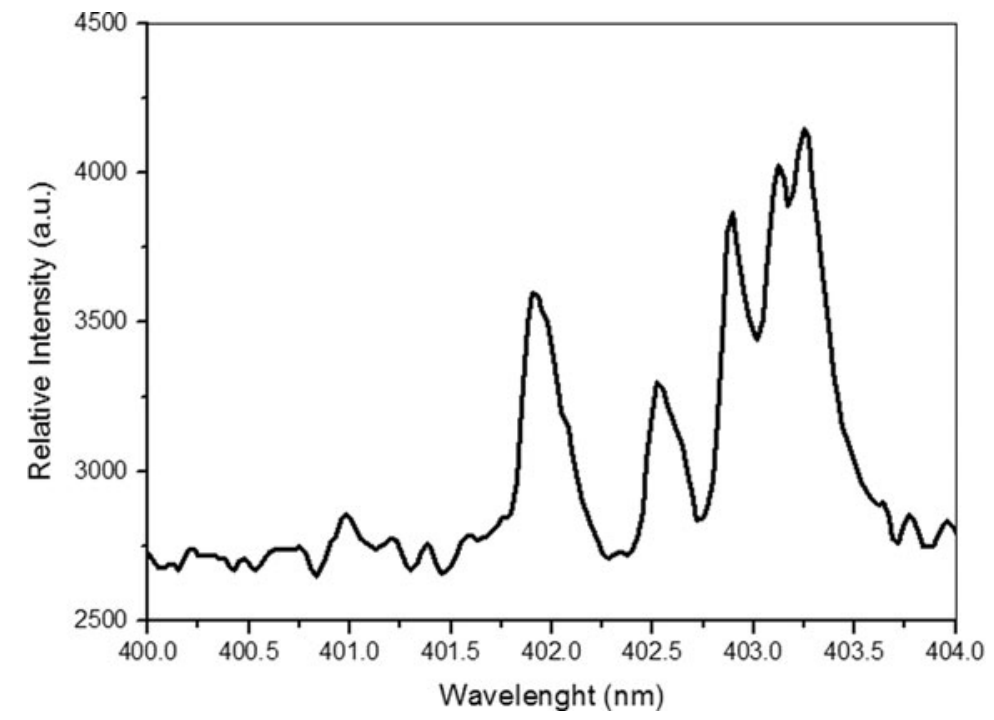

Figure 5. Spectrum of an industrial sludge by tungsten coil atomic emission spectrometry. 
improve the sensitivity and repeatability of the analysis. The results (Table 3) showed that the limit of detection, limit of quantification, and relative standard deviation were improved by combining the signals for the three manganese emission lines.

The accuracy of the method was determined by determining $\mathrm{Mn}$ in San Joaquim Soil (NIST SRM 2709) and industrial sludge (NIST SRM 2782) reference materials. In addition, the results obtained using ICP OES were compared to the WCAES data (Table 4). In neither procedure were there any statistically significant differences (at a 95 percent confidence level) between the WCAES data and the expected Mn concentrations. The spectra obtained for the industrial sludge are presented in Figure 5.

\section{CONCLUSIONS}

A tungsten coil atomic emission spectrometer was developed using a small power supply, a tungsten coil extracted from a commercially available light bulb, and a handheld detector. This simple and fast technique enabled the simultaneous monitoring of multiple emission lines during determination of manganese in industrial sludge, alloy, and soil. Its potential portability means that WCAES may be used in field analysis. The summation of multiple emission lines improved the analytical figures of merit and minimized matrix interference effects. A slightly lower limit of detection of 0.17 milligram per liter was obtained when the signals were summed. The relative standard deviations ranged from 1.7 to 8.5 percent when the combined emission signals for the three wavelengths were used. The accuracy of the method was confirmed by analysis of two certified reference materials, and no statistically significant differences (at a 95 percent confidence level) were observed between Mn concentrations determined by WCAES and ICP OES.

\section{ACKNOWLEDGMENTS}

The authors also gratefully acknowledge the collaboration of Prof. Dr. Joaquim de Araújo Nóbrega (DQ/UFSCar).

\section{FUNDING}

This work was supported by grants from the São Paulo State Research Foundation (FAPESP, process no. 2007/51448-0), the Conselho Nacional de Desenvolvimento Científico e Tecnológico (CNPq), and the Coordenação de Aperfeiçoamento de Nível Superior (CAPES).

\section{REFERENCES}

Berndt, H., and G. Schaldach. 1988. Simple low-cost tungsten-coil atomiser for electrothermal atomic absorption spectrometry. Journal of Analytical Atomic Spectrometry 3: 709-12. doi:10.1039/ja9880300709 
Cotton, F. A., and G. Wilkinson. 1982. Química inorgânica. Rio de Janeiro, Brazil: Livros Técnicos e Científicos Editora.

Donati, G. L., M. H. Gonzalez, J. A. Nóbrega, and B. T. Jones. 2010. Multi-wavelength determination of cobalt by tungsten coil atomic emission spectrometry. Analytical Letters 43: 1723-33. doi:10.1080/00032711003653825

Donati, G. L., R. B. Wildman, and B. T. Jones. 2011. A new atomization cell for trace metal determination by tungsten coil atomic spectrometry. Analytica Chimica Acta 688: 36-42. doi:10.1016/j.aca.2010.12.036

Emsley, J. 1989. The Elements, 1st ed., Oxford.

Giné, M. F., F. J. Krug, V. A. Sass, B. F. Reis, J. A. Nóbrega, and H. Berndt. 1993. Determination of cadmium in biological materials by tungsten coil atomic absorption spectrometry. Journal of Analytical Atomic Spectrometry 8: 243-45. doi:10.1039/ja9930800243

Gu, J., S. Hanna, and B. T. Jones. 2011. A portable tungsten coil atomic emission spectrometer for the simultaneous determination of metals in water and soil sample. Analytical Sciences 27: 523-27. doi:10.2116/analsci.27.523

Gu, J., S. R. Oliveira, G. L. Donati, J. A. G. Neto, and B. T. Jones. 2011. Rugged, portable tungsten coil atomic emission spectrometer. Analytical Chemistry 83: 2526-31. doi:10.1021/ ac1027897

Hou, X., and B. T. Jones. 2002. Tungsten devices in analytical atomic spectrometry. Spectrochimica Acta Part B: Atomic Spectroscopy 57: 659-88. doi:10.1016/S0584-8547(02)00014-9

Hou, X., K. E. Levine, A. Salido, B. T. Jones, M. Ezer, S. Elwood, and J. B. Simeonsson. 2001. Tungsten coil devices in atomic spectrometry: Absorption, fluorescence, and emission. Analytical Sciences 17: 175-80. doi:10.2116/analsci.17.175

http://physics.nist.gov/PhysRefData/ASD/index.html (accessed June 02, 2015).

Nóbrega, J. A., M. M. Silva, P. V. Oliveira, F. J. Krug, and N. Baccan. 1995. Espectrometria atômica com atomização eletrotérmica em superfícies metálicas. Quimica Nova 18(6): $555-62$.

Ohta, K. 1987. Atomic emission spectrometry of sodium with electrothermal metal microtube. Fresenius' Zeitschrift für Analytische Chemie 326: 132-34. doi:10.1007/BF00468496

Ohta, K., S. Itoh, and T. Mizuno. 1991. Electrothermal atomic-emission spectrometric determination of lithium with a metal-tube atomizer and a matrix modifier. Talanta 38 (3): 325-28. doi:10.1016/0039-9140(91)80055-5

Oliveira, P. V., M. Catanho, J. A. Nóbrega, and P. O. Luccas. 2000. Avaliação de programas de aquecimento para espectrometria de absorção atômica com atomização eletrotérmica em filamento de tungstênio. Química Nova 23(5): 706-08. doi:10.1590/S010040422000000500022

Queiroz, Z. F., P. V. Oliveira, J. A. Nóbrega, C. S. Silva, I. A. Rufini, S. S. de Sousa, and F. J. Krug. 2002. Surface and gas phase temperatures of a tungsten coil atomizer. Spectrochimica Acta Part B: Atomic Spectroscopy 57(11): 1789-99. doi:10.1016/s0584-8547(02)00146-5

Ribeiro, A. S., M. A. Z. Arruda, and S. Cadore. 2002. Espectrometria de absorção atômica com atomização eletrotérmica em filamento de tungstênio: Uma re-visão critica. Química Nova 25(3): 396-405. doi:10.1590/s0100-40422002000300012

Rust, J. A., J. A. Nóbrega, C. P. Calloway, Jr., and B. T. Jones. 2006. Tungsten coil atomic emission spectrometry. Spectrochimica Acta Part B: Atomic Spectroscopy 61: 225-29. doi:10.1016/j.sab.2005.12.009

Santos, L. N., M. H. Gonzalez, M. F. Moura, G. L. Donati, and J. A. Nóbrega. 2012. In situ digestion for the determination of $\mathrm{Ca}$ in beverages by tungsten coil atomic emission spectrometry. Talanta 97: 285-90. doi:10.1016/j.talanta.2012.04.032

Suzuki, M., and K. Ohta. 1981. Electrothermal atomization of calcium and strontium in a molybdenum micro-tube. Talanta 28: 177-81. doi:10.1016/0039-9140(81)80008-2 
Suzuki, M., and K. Ohta. 1982. Determination of strontium in biological samples by atomic emission spectrometry with electrothermal atomization. Fresenius' Zeitschrift für Analytische Chemie 313: 34-37. doi:10.1007/BF00483714

Suzuki, M., and K. Ohta. 1985. Atomic emission spectrometry with metal microtube atomization. Analytical Chemistry 57: 26-29. doi:10.1021/ac00279a011

Weast, R. C. 1989. Handbook of Chemistry and Physics, 64th ed., Boca Raton, FL: CRC Press. 